\title{
Variation of Latent Heat Flux and Canopy Temperature over Potato Crop Governed by Soil Moisture
}

\author{
S. Thakur*, S. Banerjee and A. Mukherjee \\ Department of Agricultural Meteorology and Physics, B.C.K.V, Mohanpur, \\ Nadia -741252 (W.B), India \\ *Corresponding author
}

\section{A B S T R A C T}

Considering the increased demand of water for agricultural sector estimation of evapotranspirational (ET) losses becomes significantly important for its proper utilization. The latent energy flux (LE) can provide better solution to water management as it is directly related to evapotranspiration. Canopy temperature is a good indicator of water stress in the soil as it is inversely related with transpiration. The present study was carried out to

\section{Keywords}

Evapotranspiration, LE, BREB, CT, Potato.

Article Info

Accepted:

04 September 2017

Available Online:

10 October 2017 investigate the influence of moisture on surface energy balance component (LE) and canopy temperature (CT) over potato field during 2014-15 and 2015-16 growing season .With the help of micromet tower observation were taken hourly basis on temperature, net radiation, and wind speed at seven days interval, covering different growth stages. Simultaneously the data on canopy temperature and soil moisture were also recorded. Bowen ratio energy balance approach (BREB) was used to compute LE. It was seen that the value of LE was higher during vegetative stage and tuber bulking stage in both the growing season. The peak LE value observed was $266 \mathrm{wm}^{-2}$ in $2014-15$ and $601 \mathrm{wm}^{-2}$ in 2015-16 during vegetative stage when moisture condition was also higher. The lower LE values were found during emergence as well as $50 \%$ leaf drying stage in both the growing period, when moisture status was considerably lower. It was also observed from the study that canopy temperature was higher during maturity stage of the crop when the field was almost dry. A significant negative correlation was found (0.86) with the available soil moisture. Thus canopy temperature may be used as an indicator of soil moisture stress and estimation of ET through latent heat flux could be useful for scheduling of irrigation or better management of water.

\section{Introduction}

The microclimate of plant communities varied with energy balance, turbulent exchange and thermal status of the soil surface. Available net radiation is the balance between incoming and outgoing radiation which is the main source of energy in the earth system. The balance of energy at the earth's surface is closely associated with the overlying atmospheric boundary layer (Roxy et al.,
2014). The total available energy and partitioning of it into different components such as sensible heat (h), latent heat (LE) and soil heat fluxes $(G)$ influences the production of the crop very strongly. Numerous studies have been made to investigate the nature of radiation balance at the crop surface. Huband and Monteith (1986) studied radiative surface temperature and energy balance of a wheat 
canopy and estimated the latent and sensible heat fluxes. Bezerra et al., (2014) found that energy balance partitioning and ET varies seasonally along each growth stages of cotton. Ding et al., (2013) studied that over banana crop latent heat flux was the dominant among other component of energy balance. The energy balance closure is based on conservation of energy. This should lead to the available energy in an agricultural ecosystem equalling the energy involved in the various processes (Pardo et al.,). The latent heat flux (LE) is directly related with the evapo-transpiration and thus estimation of LE can provide better solution to water management and monitoring of water resources as well.

India is the second largest potato producing nation in the world with a production of 438 lakh tonnes. It is widely cultivated across the country and has become a staple vegetable in many parts of the India. The crop is very sensitive to water stress due to its shallow and fibrous root system and thus the tuber yield may be considerably reduced by soil water deficit. As water requirement of potato is supposed to be very high $(500-600 \mathrm{~mm})$ the scheduling of irrigation at optimum moisture level during critical stages and sub-optimum level during rest of the period may result into about $30 \%$ saving in water requirement of the crop. Besides, water supply and scheduling have also important impact on quality of tuber. Estimation of LE thus can give us the idea for proper management of water as it is related with ET. High leaf temperature is also a consequence of water stress as the plant loses the ability for transpirational cooling under limited water condition ( $\mathrm{Lu}$ et al., 1997). Measurement of canopy temperature with infrared thermometers has been an efficient tool for irrigation scheduling in semi-arid and arid conditions (Evett et al., 2000) and hence moisture status of soil as well as plant can also be indicated by canopy temperature of the crop.
The main objective of this study are: (1) to estimate latent heat flux (LE) from Bowen ratio energy balance approach and how it is influenced by moisture status of the crop and (2) to evaluate the relationship between canopy thermal environment and soil moisture status.

\section{Materials and Methods}

\section{Experimental site}

The field experiment was conducted in the University Farm of Bidhan Chandra Krishi Viswavidyalaya, Kalyani, West Bengal (Latitude: $22^{\circ} 57^{\prime} \mathrm{N}$, Longitude: $88^{\circ} 20^{\prime} \mathrm{E}$ and Altitude: $9.75 \mathrm{~m}$ above mean sea level).The climate of the zone is sub-tropical with an average annual rainfall of 1467.5.The land situation is medium to low condition and the assured irrigation facility from deep tubewell exists along with provision of good drainage. The soil of the experimental field was alluvial in nature (Entisol) and silty clay in texture.

\section{Field investigation}

Potato (Solanum tuberosum) was taken as the test crop above which the energy balance was studied.

The crop was sown on $5^{\text {th }}$ December and 8th December respectively during 2014-15 and 2015-16 growing seasons. The plant to plant distance was $15 \mathrm{~cm}$ and row to row distance was $50 \mathrm{~cm}$. The Kufri Surya variety was grown and standard package of practices were followed as per the recommendation given for New Alluvial Zone of West Bengal.

\section{Meteorological observations}

\section{Net radiation}

With the help of net radiometer (Make National Instrument and Calibrated by IMD, Pune), measurements of net radiation over the 
crop was made throughout the crop growth period at seven days interval. The observations were taken at hourly intervals from 9.00 hours to 15.00 hours keeping the instruments at $1.0 \mathrm{~m}$ above the crop height.

\section{Canopy temperature (CT)}

Canopy temperature was measured with the help of Infrared Thermometer and the values were recorded in ${ }^{0} \mathrm{C}$. Canopy temperature was taken at hourly intervals from 9.00 hours to 15.00 hours.

The measurements were taken from four sides of the experimental plot from $1 \mathrm{~m}$ distance at an angle of $30^{\circ}$ (in respect to horizontal plane) to the crop. The final CT value was taken as the average of these four values at a particular time.

\section{Soil temperature}

Soil temperature at $5 \mathrm{~cm}$ and $15 \mathrm{~cm}$ depth from the ground surface was measured with soil thermometer. The thermometers were inserted into the soil at an angle of $60^{\circ}$ and readings were recorded at hourly interval in between two rows of potato crop.

\section{Air temperature (AT) and Actual vapour pressure (AVP)}

Psychrometer was installed at a height of crop surface and $1.0 \mathrm{~m}$ above the crop surface. The dry bulb reading was taken at hourly interval from 9.00 to 15.00 hours to measure the AT. Both the dry and wet bulb readings were considered to calculate AVP at the above said heights.

\section{Soil moisture}

Moisture content in the upper surface of the soil has been calculated by gravimetric method.

\section{Calculation procedure}

\section{Bowen ratio}

Bowen (1926) introduced a relationship between LE and $\mathrm{H}$ known as Bowen Ratio $(\beta)$. Considering the equation of Bowen ratio as follows, the value of that ratio can be determined as

$\beta=\frac{H}{L E}=\frac{\rho_{a} C_{p} \cdot K_{h} \cdot \frac{d T}{d Z}}{\rho_{a} \cdot \frac{\varepsilon}{P} \cdot L \cdot K w \cdot \frac{d e}{d z}} \ldots(1)$

Where, $\mathrm{H}$ and LE are in $\mathrm{wm}^{-2}$

$\mathrm{L}$ is the latent heat of vaporization of water $\left(580 \mathrm{cal} / \mathrm{cm}^{3}\right), \rho_{\mathrm{a}}$ is the density of air $1.145^{*} 10^{-}$ ${ }^{3}\left(\mathrm{~g} / \mathrm{cm}^{3}\right), C_{P}$ is specific heat of dry air at constant pressure $\left(0.24 \mathrm{cal} / \mathrm{g} /{ }^{0} \mathrm{C}\right), \varepsilon$ is the ratio of molecular weight of water to that of air (0.622), $\mathrm{P}$ atmospheric pressure at vapour pressure at the site $(\mathrm{mb}), \mathrm{Kh}$ and $\mathrm{Kw}$ is eddy diffusivity of water vapour and sensible heat $\left(\mathrm{wm}^{-2}\right), \mathrm{de} / \mathrm{dz}$ is vapour pressure gradient $(\mathrm{mm} /$ day), $\mathrm{dT} / \mathrm{dz}$ is vertical temperature gradient

After simplifying, we get,

$\frac{C p * P}{\varepsilon . L} * \frac{K_{h}}{K_{w}} * \frac{d T}{d e}$

Where, $\mathrm{C}_{\mathrm{P}} \mathrm{P} / \varepsilon \mathrm{L}=\gamma$ is the psychrometric constant $\left(0.0623 \mathrm{k} \mathrm{Pa}^{0} \mathrm{C}^{-1}\right)$ and if further simplified with Raynolds analogy $\mathrm{K}_{\mathrm{h}}=\mathrm{K}_{\mathrm{w}}$

Therefore, $\beta=\gamma .1 . \mathrm{dT} / \mathrm{de}$

\section{Soil heat flux}

In this study soil heat flux is computed using Fourier's law. According to Fourier's law soil heat flux can be written as: 
$(\mathrm{G})=-\mathrm{K}(\mathrm{dT} / \mathrm{dx})$

Where, $\mathrm{G}=$ Soil heat flux $\left(\mathrm{J} / \mathrm{m}^{2} / \mathrm{s}\right), \mathrm{dT} / \mathrm{dx}=$ Temperature gradients, $\mathrm{k}=$ Thermal conductivity $\left({ }^{\circ} \mathrm{C} / \mathrm{m}\right)$, value of which is depends on texture and moisture content of the soil.

Negative sign of which indicates the flux and the gradients are in opposite direction.

\section{Latent heat flux}

Latent heat flux is calculated by using the following formula:

$\mathrm{LE}=[(\mathrm{Rn}-\mathrm{G}) /(1+\beta)]$,

Where, $\mathrm{LE}=$ Latent heat flux, $\mathrm{Rn}=$ Net Radiation, $\beta=$ Bowen ratio

\section{Sensible heat flux}

Sensible heat flux is computed by residual method using energy balance equation as follows:

$\mathrm{H}=$ Rn-LE-G, Where $\mathrm{H}=$ Sensible heat flux

\section{Results and Discussion}

\section{Variation of Bowen ratio ( $\beta$ )}

From the variation of the temperature gradient and vapour pressure gradient, the Bowen ratio variation was assessed for potato growing season. In the present study, the values of $\beta$ were positive during most of the stages in both the years (Table 1). The value ranged between -0.30 to 0.07 during 2014-15 and 0.35 to 0.32 during 2015-16 growing season. During vegetative stage the value of $\beta$ was found to be lower due to good moisture condition and canopy coverage of the crop. However the value of $\beta$ was relatively higher at $50 \%$ leaf drying stage. The higher value of $\beta$ indicates that more amount of energy is partitioned into sensible heat which is used for heating the atmosphere rather than latent heat from the surface (Neog et al., 2005). In the present study also higher value of $\beta$ (0.060.08 ) was found during maturity stage of the crop.

\section{Latent heat flux (LE) over different growth stages}

During the whole growing period of the crop for 2014-15 and 15-16 it was observed that magnitude of LE was higher than other two components which may be due to strong dependence of LE on Rn (Table 2). During emergence period, values of $\mathrm{G}$ and $\mathrm{H}$ were comparatively higher than that of other growth stages, due to low canopy cover (Table 2). Higher values of LE were observed in vegetative and tuber bulking stages (Figs.1 and 2) in both crop seasons, which is due to the high rate of evapo-transpiration and higher canopy coverage during the stages. Moisture condition of the field was also high during these stages as irrigation were given in both vegetative and tuber initiation stages. During these phenophases the peak values of LE observed were $466 \mathrm{Wm}^{-2}$ to $362 \mathrm{Wm}^{-2}$ (2014-15) and $601 \mathrm{Wm}^{-2}$ to $386 \mathrm{Wm}^{-2}$ (201516). For the total growing period it was observed that the LE values were lower in emergence and 50\% leaf drying stages and during that period moisture level of the field were also lower. During maturity stage the irrigation is generally withdrawn, hence lack of moisture in the field leads to more energy partitioning into sensible heat flux as compared to other stages. But the variation of LE was not only due to the varying moisture condition of the field, it was also dependent on some meteorological parameters. Cloud cover was one of those factors which also govern the ET process. In some observation date, we got lower values of LE due to presence of higher cloud cover on that point 
of observation although the moisture condition of the field was good. Due to high cloud cover, the vapour pressure deficit governed the magnitude of LE instead of soil moisture status (Table 3).

Table.1 Measured actual vapour pressure and ambient temperature (Measurement time 12:00 hours) at different heights over potato crop and estimated Bowen ratio

\begin{tabular}{|c|c|c|c|c|c|c|}
\hline Crop season & $\begin{array}{l}\text { Date of } \\
\text { observation }\end{array}$ & AVP & & AT & & Bowen ratio \\
\hline 2015 & 02.01 .15 & Below* & Above** & Below* & Above** & 0.02 \\
\hline & & 30.15 & 26.49 & 26.2 & 26.1 & \\
\hline & 09.01 .15 & 23.99 & 20.94 & 25 & 26.4 & 0.07 \\
\hline & 16.01 .15 & 41.82 & 23.51 & 28.4 & 28 & 0.01 \\
\hline & 23.01 .15 & 45.05 & 29.11 & 32.5 & 30.8 & -0.03 \\
\hline & 30.01 .15 & 27.61 & 15.95 & 28 & 27.5 & 0.02 \\
\hline & 06.02 .15 & 42.1 & 27.32 & 30.4 & 31.3 & 0.03 \\
\hline & 13.02 .15 & 49.11 & 27.24 & 34 & 32.4 & 0.06 \\
\hline 2016 & 16.12 .15 & 20.29 & 14.84 & 25.2 & 24.9 & 0.04 \\
\hline & 23.12 .15 & 19.52 & 16.1 & 23.6 & 22.2 & 0.27 \\
\hline & 30.12 .15 & 20.05 & 18.83 & 25.5 & 25.6 & 0.32 \\
\hline & 07.01 .16 & 31.46 & 20.49 & 26.6 & 25.8 & 0.05 \\
\hline & 14.01 .16 & 22.96 & 19.16 & 24.5 & 26.3 & -0.31 \\
\hline & 21.01 .16 & 19.89 & 17.27 & 20.5 & 21.9 & -0.35 \\
\hline & 28.01 .16 & 25.46 & 16.07 & 23.5 & 22.1 & 0.10 \\
\hline & 5.02 .16 & 32.92 & 18.96 & 26.5 & 27.4 & -0.04 \\
\hline & 12.02 .16 & 31.82 & 27.09 & 27.5 & 27.3 & 0.03 \\
\hline & 19.02 .16 & 40.27 & 25.96 & 33 & 32.3 & 0.05 \\
\hline & 26.02 .16 & 34.83 & 27.5 & 28 & 27.1 & 0.08 \\
\hline
\end{tabular}

*Below $=$ Measured at crop height

$* *$ above $=$ Measured at $1.0 \mathrm{~m}$ above the crop height

Table.2 Variation of net radiation, soil heat flux and latent heat flux

\begin{tabular}{|c|c|c|c|c|}
\hline Year & Date of Observation & $\mathbf{R}_{\mathbf{n}}$ & $\mathbf{G}$ & LE \\
\hline \multirow[t]{7}{*}{2015} & 02.01 .15 & 151.7 & 23.5 & 128.2 \\
\hline & 09.01 .15 & 353.9 & 29.0 & 362.1 \\
\hline & 16.01 .15 & 448.7 & 41.4 & 401.5 \\
\hline & 23.01 .15 & 436.1 & 48.3 & 466.2 \\
\hline & 30.01 .15 & 486.7 & 48.3 & 426.2 \\
\hline & 06.02 .15 & 353.9 & 40.1 & 327.0 \\
\hline & 13.02 .15 & 499.3 & 59.4 & 219.6 \\
\hline \multirow[t]{10}{*}{2016} & 16.12 .15 & 316.0 & 32.5 & 273.6 \\
\hline & 23.12 .15 & 183.3 & 9.1 & 137.1 \\
\hline & 30.12 .15 & 271.8 & 11.2 & 275.5 \\
\hline & 14.01 .16 & 353.9 & 23.0 & 481.4 \\
\hline & 21.01 .16 & 404.5 & 15.0 & 601.6 \\
\hline & 28.01 .16 & 252.8 & 5.6 & 225.0 \\
\hline & 5.02 .16 & 404.5 & 34.8 & 386.1 \\
\hline & 12.02 .16 & 214.9 & 41.4 & 186.4 \\
\hline & 19.02 .16 & 429.8 & 39.0 & 378.6 \\
\hline & 26.02 .16 & 316.0 & 37.2 & 309.5 \\
\hline
\end{tabular}


Table.3 Variation of latent heat flux (LE) with different soil moisture

\begin{tabular}{|l|l|l|l|}
\hline Date & LE & SM & CC \\
\hline 16.12 .15 & 202.60 & 17.93 & 0 \\
\hline 23.12 .15 & 129.84 & 16.62 & 6 \\
\hline 30.12 .15 & 235.76 & 17.15 & 0 \\
\hline 7.01 .15 & 189.67 & 16.99 & 2 \\
\hline 14.01 .16 & 244.85 & 17.69 & 0 \\
\hline 21.01 .16 & 323.92 & 16.98 & 0 \\
\hline 28.01 .16 & 184.29 & 16.72 & 6 \\
\hline 05.02 .16 & 290.64 & 14.91 & 0 \\
\hline 12.02 .16 & 143.35 & 17.7 & 8 \\
\hline
\end{tabular}

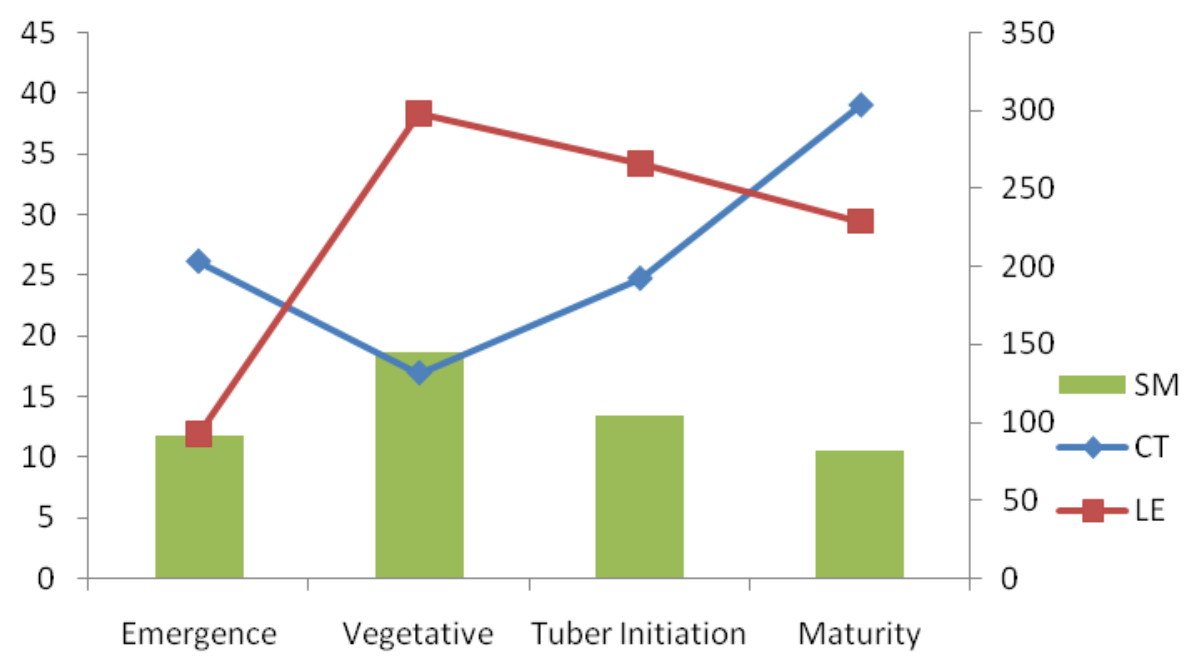

Fig 1. Variation of LE and CT with soil moisture (201415)

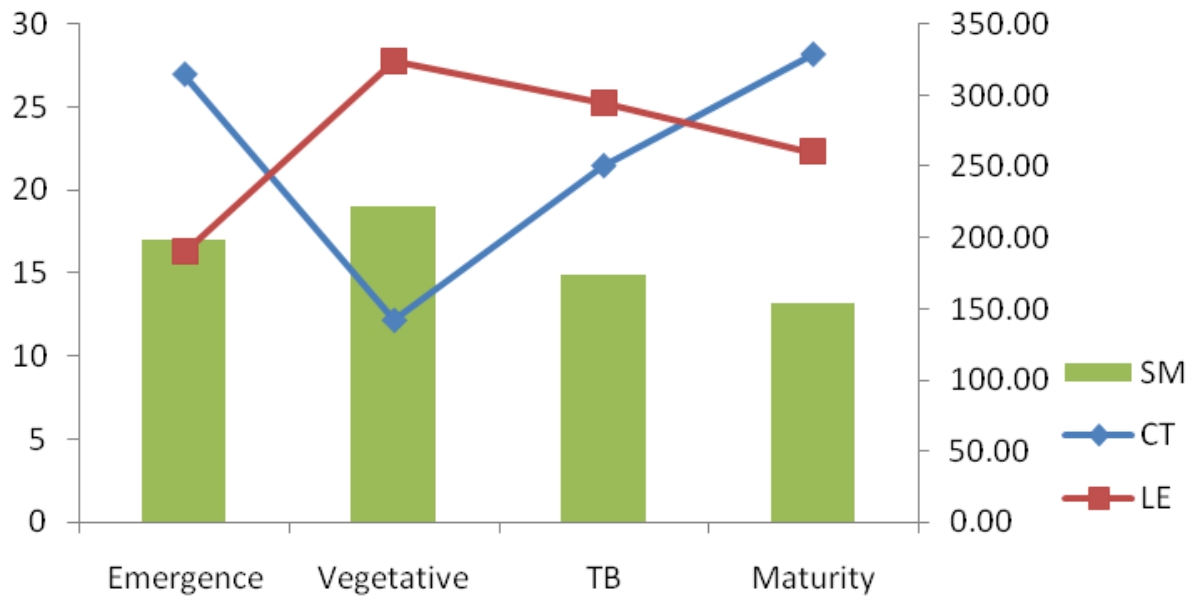

Fig 2. Variation of LE and CT with soil moisture (2015-

16) 
Variation of canopy temperature influenced by soil moisture

During the growing period of potato (2014-15 and 2015-16) canopy temperature (CT) as well as ambient temperature was taken on hourly basis from $9.00 \mathrm{hrs}$ to $16.00 \mathrm{hrs}$. The variations of canopy temperature from hour to hour and from one phenophase to another were also noticed. The highest canopy temperature was found at $50 \%$ leaf drying stage when the crop almost reached the maturity condition $\left(38.8^{\circ} \mathrm{C}\right)$ and the field condition was also dry. At that time the CATD (Canopy Air temperature difference) value was also higher $\left(0.10^{\circ} \mathrm{C}\right)$ indicating the stress condition of the crop during that time. In the early and mid-growing stages of the crop, when irrigations were applied or moisture condition was good, canopy temperature of the crop were lower than the air temperature, which caused the lower value of CATD. It indicated that during that time crop was in non-stress condition. The diurnal pattern of CT revealed that the value of CT was lower in the morning hours and varies without following any particular trend, but most of the cases peak values were observed at $14.00 \mathrm{hrs}$. High $\mathrm{R}^{2}$ value (-0.86) indicates that canopy temperature strongly correlated with the available soil moisture and may be used as an indicator of crop water stress.

It has been seen from the study that higher value of $\beta$ was observed during maturity stage of the crop when field was almost dry condition. This clearly indicates that higher amount energy was partitioned into sensible heat flux during the maturity stage of the crop, although LE was dominant energy balance component throughout the growing season. The peak value of LE was observed during vegetative phase of the crop when moisture level of the field and leaf area was very high and rate of ET was also higher. The canopy temperature of the crop was significantly higher when field condition was dry and lower values were observed when good moisture condition prevailed in the field. Higher value of CT was also observed during maturity stage of the crop. Therefore it can be concluded that LE and Canopy temperature of the crop are strongly influenced by the available soil moisture in the field and canopy structure of the crop.

\section{References}

Bezerra B.G., Bezerra J.R.C, Da silva B.B 2014. Surface energy exchange and evapotranspiration from cotton crop under full irrigation conditions in the Rio Grande do Norte State, Brazilian Semi-Arid. http://dx.doi.org/10.1590/16784499.0245.

Bowen, I. S., 1926. The ratio of heat losses by conduction and by evaporation from any water surface. Phys. Rev. 27: 779787.

Ding, Z., Wen, Z., Wu, R. et al., Surface energy balance measurements over a banana

Evett SR, Howell AD, Schneider DR, Upchurch DF, Wanjura DF. 2000. Automatic drip irrigation of corn and soybean. In Proc. 4th Decennial Natl Irrigation Symp401-408.

Huband, N., D. S. and Monteith, J. L. 1986. Radiative surface temperature and energy balance of a wheat canopy. Boundary Layer Meteorology.36 (1): 107-116.

Lu, Z., Chen J, Percy RvG, Zeiger E. 1997. Photosynthetic rate, stomatal conductance and leaf area in two cotton species (Gossypium barbadense and Gossypium hirsutum) and their relation with heat resistant and yield. Aust J Plant Physiol 24:693-700

Neog, P., Srivastava, A.K. and Chakravarty, N.V.K. 2005. Estimation and 
Application of Bowen Ratio Fluxes over Crop Surfaces - An Overview. J. Agric. Physics, 5: 36-45.

Pardo, N., Sanchez, M.L., Perez, I.A. and Garcia, M.A. 2015. Energy balance and partitioning over a rotating rapeseed crop. Agricultural Water Management, 161: 31-40.
Plantation in South China. Theor Appl Climatol 2013. 114: 349.

Roxy, M. S., Sumithranand, V. B. and Renuka, G. 2014. Soil heat flux and day time surface energy balance closure at astronomical observatory, Thiruvananthapuram, south Kerala. $J$. Earth Syst. Sci. 123(4): 741-750.

\section{How to cite this article:}

Thakur, S., S. Banerjee and Mukherjee, A. 2017. Variation of Latent Heat Flux and Canopy Temperature over Potato Crop Governed by Soil Moisture. Int.J.Curr.Microbiol.App.Sci. 6(10): 130-137. doi: https://doi.org/10.20546/ijcmas.2017.610.016 